DOI: 10.20472/IAC.2018.935.028

LEE KWANGBAE

Sunchon National University, Korea, Republic of

\title{
ANALYSIS OF EXPORT STRUCTURE OF PORTS USING GROWTH-RATE DIFFERENTIAL ANALYSIS
}

\begin{abstract}
:
Shift-share analysis is a decomposition technique widely used in regional studies to identify sectoral growth effects of economic variables. As globalization progresses rapidly, much attention has been paid to the extension of shift-share analysis, but the most important phenomenon is to extend the traditional shift-share analysis to international trade. Henderson (1962) developed a regional growth rate differential analysis that shows growth contribution by sector.

This paper analyzed the export fluctuation by factors of 10 major export items of Gwangyang Port and Incheon Port by applying shift-share analysis and growth rate differential analysis. This paper differs from the previous studies in two respects. First, it applies the shift-share analysis and the regional growth rate differential analysis so that each technique can complement each other. Second, the export weight is analyzed instead of the export amount which focuses on the existing research.

In the case of Gwangyang Port, the regional allocation effect of nine items out of 10 items has a positive sign, but in the growth rate differential analysis, the competitive factors of most items have negative signs, and the analysis shows opposite results.

In the case of Incheon port, the shift-share analysis shows that the industrial structure effect and regional allocation effect have positive signs in three items. However, in the regional growth rate differential analysis, both weighting factor and competitiveness factor have no positive sign. This analysis implies that both techniques should be applied together in order to accurately resolve and evaluate port export structure and competitiveness.
\end{abstract}

\section{Keywords:}

growth rate differential analysis, shift-share analysis, industry-mix effect, regional competitive effect, rate component, weight component

JEL Classification: A10 